YURI, J.E.; RESENDE, G.M.; RODRIGUES JÚNIOR, J.C.; MOTA, J.H.; SOUZA, R.J. Efeito de composto orgânico sobre a produção e características comerciais de alface americana. Horticultura Brasileira, Brasília, v.22, n.1, p. 127-130, jan-mar 2004.

\title{
Efeito de composto orgânico sobre a produção e características comer- ciais de alface americana
}

\author{
Jony E. Yuri' ${ }^{1}$, Geraldo M. de Resende ${ }^{2}$; Juarez C. Rodrigues Júnior ${ }^{3}$; José Hortêncio Mota ${ }^{1}$; Rovilson J. \\ de Souza ${ }^{1}$ \\ ${ }^{1}$ UFLA, C. Postal 37, 37200-000 Lavras-MG; E-mail: jonyyuri@uol.com.br; ${ }^{2}$ Embrapa Semi-Árido, C. Postal 23, 56300-000 Petrolina- \\ PE; ${ }^{3}$ Agromax, R. Tiradentes, 12, 37750-000 Machado-MG
}

\section{RESUMO}

Doses de composto orgânico foram avaliadas na produtividade e qualidade da alface americana em um ensaio em Três Pontas, de 08/07 a 30/08/02. O delineamento utilizado foi em blocos casualizados com quatro repetições, sendo os tratamentos constituídos por cinco doses de composto orgânico $(0,0 ; 20,0 ; 40,0 ; 60,0$ e $\left.80,0 \mathrm{t} \mathrm{ha}^{-1}\right)$. A massa fresca total evidenciou um efeito quadrático, na qual a produtividade máxima de $914,2 \mathrm{~g}$ planta $^{-1}$, foi obtida com a dose de 59,4 t ha ${ }^{-1}$ do composto orgânico. Para massa fresca comercial, a máxima produtividade $\left(634,3 \mathrm{~g} \mathrm{planta}^{-1}\right)$, foi obtida com a dose de $56,1 \mathrm{t} \mathrm{ha}^{-1}$. A maior circunferência da cabeça comercial $(41,4$ $\mathrm{cm}$ ), foi obtida com a dose de $53,7 \mathrm{t} \mathrm{ha}^{-1}$. A dose de $42,7 \mathrm{tha}^{-1}$ proporcionou um comprimento de caule máximo de $3,9 \mathrm{~cm}$. Diante desses resultados, pode-se concluir que o uso de 56,0 $\mathrm{t} \mathrm{ha}^{-1}$ de composto orgânico aplicado em pré-plantio, proporciona aumento de rendimento e qualidade comercial da alface americana.

Palavras-chave: Lactuca sativa L., produtividade, circunferência da cabeça, comprimento do caule, adubo orgânico.

\begin{abstract}
Effect of organic compost on crisp head lettuce production and commercial characteristics

Doses of organic compost were evaluated on crisp head lettuce production and quality in an experiment conduced in Três Pontas, Brazil, from July $8^{\text {th }}$ to August $30^{\text {th }}$. The experimental design was in randomized complete blocks with four replicates, the treatments being constituted by five doses of organic compost $(0.0 ; 20.0 ; 40.0$; 60.0 and $80.0 \mathrm{tha}^{-1}$ ). Total fresh matter showed a quadratic effect, in which the maximum yield of $914.2 \mathrm{~g}$ plant $^{-1}$ was obtained with the dose of $59.4 \mathrm{tha}^{-1}$ of organic compost. For commercial fresh matter, the maximum yield ( $\left.634.3 \mathrm{~g} \mathrm{plant}^{-1}\right)$ was obtained with the dose of $56.1 \mathrm{t} \mathrm{ha}^{-1}$. The greatest commercial head circumference $(41.4 \mathrm{~cm})$ was obtained with the dose of $53.7 \mathrm{t} \mathrm{ha}^{-1}$. The dose of $42.7 \mathrm{t} \mathrm{ha}^{-1}$ caused a maximum stem length of $3.9 \mathrm{~cm}$. These results permit to conclude that the use of $56.0 \mathrm{tha}^{-1}$ of organic compost applied in pre plant provides an increase in yield and commercial quality of crisp head lettuce.
\end{abstract}

Keywords: Lactuca sativa L., yield, head circumference, stem length, organic manure.

(Recebido para publicação em 5 de maio de 2003 e aceito em 28 de novembro de 2003)

A tualmente, com o aumento do número de redes de lanchonetes do tipo "fast-foods", vem se destacando um grupo de alface denominada "crisp head lettuce" ou tipo "americana" (Maluf, 2000). Esse destaque se deve, principalmente, às características apresentadas por este grupo. A alface americana se diferencia dos demais grupos por apresentar folhas externas de coloração verde-escura, folhas internas de coloração amarela ou branca, imbricadas, semelhantes ao repolho e crocantes (Yuri et al., 2002). Apresenta também maior vida pós-colheita, possibilitando o transporte a longas distâncias (Decoteau et al., 1995).

Em relação à alface americana destinada a uma rede de lanchonetes, temse observado que, produtores do sul de Minas Gerais realizam a produção baseada, principalmente, no uso excessivo de fertilizantes minerais. Uma das alternativas para contornar esse tipo de problema estaria no uso de compostos orgânicos. Tendo em vista o fato de o sul de Minas Gerais ser grande produtor de café e leite, forneceria com facilidade matérias primas para a confecção de compostos orgânicos de qualidade, tais como casca de grão de café, esterco de curral e capineiras. As altas produtividades alcançadas por uso intensivo de adubos minerais $\mathrm{e}$ agrotóxicos têm sido questionados nos últimos anos, não só pelas contradições econômicas e ecológicas, mas também por desprezar aspectos qualitativos importantes da produção (Santos et. al., 1994). Considerando-se este aspecto, e também em virtude do alto custo de fertilizantes minerais, tem-se cultivado hortaliças com adubos orgânicos de varias origens, visando melhorar as propriedades físicas e químicas do solo (Costa, 1994).
O uso de composto orgânico permite melhora na fertilidade, além de ser excelente condicionador de solo, melhorando suas características físicas, químicas e biológicas, como retenção de água, agregação, porosidade, aumento na capacidade de troca de cátions, aumento da fertilidade e aumento da vida microbiana do solo, entretanto, o valor fertilizante do composto depende do material utilizado como matéria prima (Miyasaka et al., 1997).

Diversos autores relatam a aplicação de adubos orgânicos proporcionando aumentos na produtividade e qualidade da alface. Aumentos lineares no peso da cabeça foram obtidos com doses de até $10,8 \mathrm{~kg} \mathrm{~m}^{-2}$ de esterco de curral (Schneider, 1983). A aplicação de esterco de cama de aviário aumentou o rendimento de matéria seca em plantas de alface, sendo os rendimentos mais elevados obtidos com as doses de 24 e $36 \mathrm{t}$ 
ha $^{-1}$ (Nicoulaud et al., 1990). Aplicando cinco doses de composto orgânico em alface, Santos et al. (1994), verificaram que a máxima produção de matéria fresca $\left(321,69\right.$ g planta $\left.^{-1}\right)$ foi obtida com a dose de 65,69 $\mathrm{t} \mathrm{ha}^{-1}$ de composto orgânico (MS), ocorrendo decréscimos com o incremento das doses. Ricci et al. (1994) estudando doses de composto orgânico e vermicomposto, verificaram produtividades iguais à testemunha, com adubação mineral, sendo que com a utilização do vermicomposto obteve-se um adicional de 3,4 t ha-1, em relação ao composto orgânico. Estudando níveis de composto orgânico, Vidigal et al. (1995) verificaram produtividades lineares, tendo a dose de $2000 \mathrm{~m}^{3} \mathrm{ha}^{-1}$ resultando em produtividade de matéria fresca de $67,20 \mathrm{t} \mathrm{ha}^{-1}$ e seca de $36,95 \mathrm{t} \mathrm{ha}^{-1}$, sendo verificados também efeito linear para diâmetro da planta. Heredia. et al. (1996), verificaram incrementos significativos no cultivo de alface $(54,61 \%)$ em relação à testemunha quando na incorporação de $14 \mathrm{tha}^{-1}$ de cama de galinha. Castro e Ferraz Jr. (1998) não verificaram diferenças estatísticas entre a adubação com uréia, sulfato de amônio e esterco de galinha na produção de matéria verde e seca da alface cultivar Aurélia. O composto orgânico, na presença da adubação mineral e na dose de $72,99 \mathrm{t} \mathrm{ha}^{-1}$, proporcionou uma produtividade de 51,62 $\mathrm{t} \mathrm{ha}^{-1}$ de alface, sendo que na ausência e com a dose de 95,67 t $\mathrm{ha}^{-1}$ alcançou uma produtividade de 51,59 $\mathrm{t} \mathrm{ha}^{-1}$ (Silva et al., 1998). Trani et al. (2000), encontraram aumento linear da produtividade quando se utilizou esterco de curral como adubo orgânico. De acordo com Fontanetti et al (2002), o uso de $40 \mathrm{t} \mathrm{ha}^{-1}$ de húmus de minhoca seguido de adubação mineral, proporcionou melhores resultados na produção de alface americana.

O presente trabalho tem como objetivo avaliar doses de composto orgânico na produtividade e qualidade da alface americana cultivada nas condições do sul de Minas Gerais.

\section{MATERIAL E MÉTODOS}

O experimento foi conduzido no município de Três Pontas (MG), à altitude de $850 \mathrm{~m}$, situado a $21^{\circ} 05^{\prime} 15^{\prime \prime} \mathrm{de}$ latitude Sul e $45^{\circ} 34^{\prime} 00^{\prime \prime}$ de longitude Oeste. O clima da região é do tipo Cwa com características de Cwb, apresentando duas estações definidas: seca (abril a setembro) e chuvosa (outubro a março), segundo a classificação climática de Köppen. O tipo de solo predominante na área é classificado como Latossolo Vermelho Distroférrico.

O delineamento utilizado foi em blocos casualizados com quatro repetições, sendo os tratamentos constituídos por cinco doses de composto orgânico $(0,0$; 20,0; 40,0; 60,0 e 80,0 t.ha-1 $)$.

O composto orgânico utilizado foi obtido seguindo as recomendações de Mendonça (1998). Confeccionando-se uma pilha de aproximadamente $1,5 \mathrm{~m}$ de altura, com camadas alternadas de casca do grão de café, esterco de curral e palha triturada de Crotalaria sp. As irrigações foram efetuadas de acordo com a necessidade, baseadas em monitoramentos semanais de umidade, realizadas visualmente. $\mathrm{O}$ revolvimento da pilha foi realizado três vezes durante o processo de cura, que se encerrou após, aproximadamente, 100 dias. A análise do material, realizada no laboratório da ESALQ revelou: umidade 46,19\%; $\mathrm{pH}$ $\left(\mathrm{CaCl}_{2}\right)=7,4$; Matéria Orgânica $=191 \mathrm{~g}$ $\mathrm{kg}^{-1} ; \mathrm{N}=1,0$ dag kg-1$; \mathrm{P}_{2} \mathrm{O}_{5}=0,48 \mathrm{dag}$ $\mathrm{kg}^{-1} ; \mathrm{K}_{2} \mathrm{O}=0,66 \mathrm{dag} \mathrm{kg}^{-1} ; \mathrm{Ca}=0,46 \mathrm{dag}$ $\mathrm{kg}^{-1} ; \mathrm{Mg}=0,2$ dag kg ${ }^{-1} ; \mathrm{S}=0,11$ dag kg-1 $\mathrm{Cu}=22 \mathrm{mg} \mathrm{kg}^{-1} ; \mathrm{Mn}=74 \mathrm{mg} \mathrm{kg}^{-1} ; \mathrm{Zn}=$ $40 \mathrm{mg} \mathrm{kg}^{-1} ; \mathrm{Fe}=22862 \mathrm{mg} \mathrm{kg}^{-1} ; \mathrm{B}=2$ $\mathrm{mg} \mathrm{kg}^{-1} ; \mathrm{Na}=1511 \mathrm{mg} \mathrm{kg}^{-1} ; \mathrm{C} / \mathrm{N}=11 / 1$.

Com 30 dias de antecedência, efetuou-se a amostragem de solo para análise, cujos resultados foram: $\mathrm{pH}\left(\mathrm{CaCl}_{2}\right)$ $=5,3 ; \mathrm{P}($ Mehlich $)=1 \mathrm{mg} \mathrm{dm}{ }^{-3} ; \mathrm{K}$ $($ Mehlich $)=51 \mathrm{mg} \mathrm{dm}^{-3} ; \mathrm{Ca}=2,0 \mathrm{cmol}_{\mathrm{c}}$ $\mathrm{dm}^{-3} ; \mathrm{Mg}=1,0 \mathrm{cmol}_{\mathrm{c}} \mathrm{dm}^{-3} ; \mathrm{H}+\mathrm{Al}=2,9$ $\mathrm{cmol}_{\mathrm{c}} \mathrm{dm}^{-3}$; Matéria Orgânica $=3,4 \mathrm{dag}$ $\mathrm{kg}^{-1} ; \mathrm{Zn}=0,5 \mathrm{mg} \mathrm{dm}^{-3} ; \mathrm{B}=0,2 \mathrm{mg} \mathrm{dm}^{-3}$; $\mathrm{SO}_{4}^{-}=5,8 \mathrm{mg} \mathrm{dm}^{-3} ; \mathrm{T}=6,0 \mathrm{cmol}_{\mathrm{c}} \mathrm{dm}^{-3}$; $\mathrm{V}=51,7 \%$. De acordo com os resultados, essa área foi previamente corrigida com calcário dolomítico, elevando a saturação por bases para 70\% (Ribeiro et $a l ., 1999)$. Três dias antes do transplantio das mudas, efetuou-se nos canteiros, a adubação de base com $65 \mathrm{~kg} \mathrm{ha}^{-1} \mathrm{de} \mathrm{N}$, $600 \mathrm{~kg} \mathrm{ha}^{-1}$ de $\mathrm{P}_{2} \mathrm{O}_{5}$ e $260 \mathrm{~kg} \mathrm{ha}^{-1}$ de $\mathrm{K}_{2} \mathrm{O}$, utilizando como fontes o adubo formulado 04-30-16 e superfosfato simples, juntamente com as doses do composto orgânico.
A área experimental foi demarcada nos canteiros centrais da área de produção. As parcelas foram padronizadas com 2,1 m de comprimento, onde se possibilitou o plantio de 28 mudas, espaçadas a cada $0,30 \mathrm{~m}$, entre plantas e $0,35 \mathrm{~m}$ entre linhas. Definiu-se como área útil, as duas linhas centrais, onde foram retiradas seis plantas para análises, descartando-se as duas plantas de cada linha nas extremidades de cada parcela.

O transplante das mudas de alface, cultivar Raider, foi realizado em 08/07/02. Após essa operação, irrigou-se a área por aspersão, diariamente, durante sete dias, até o pegamento uniforme das plantas. A partir do oitavo dia, até a colheita, a irrigação foi realizada, também diariamente, por gotejamento. Juntamente com a irrigação, realizaram-se as adubações de cobertura (fertirrigação), totalizando $40 \mathrm{~kg} \mathrm{ha}^{-1} \mathrm{de} \mathrm{Ne} 85 \mathrm{~kg} \mathrm{ha}^{-1} \mathrm{de}$ $\mathrm{K}_{2} \mathrm{O}$, utilizando-se como fontes uréia e cloreto de potássio.

Para evitar a ocorrência de lagartas e míldio (Bremia sp.), comuns nesta época do ano, foram efetuadas pulverizações semanais com produtos à base de oxicloreto de cobre e piretróides. A colheita foi efetuada em 30/08/02, quando se observou o máximo desenvolvimento vegetativo, apresentando cabeças comerciais compactas. Para a avaliação da massa fresca total, as plantas foram cortadas rente ao solo e pesadas em balança, modelo US.15/5 da marca Urano, com precisão de 5 g. Para a massa fresca comercial, foram pesadas somente as cabeças comerciais, retirando-se as folhas externas. Na seqüência, efetuou-se a medida da circunferência da cabeça comercial, passando a fita métrica ao redor da cabeça. Em relação ao comprimento de caule, cortou-se a cabeça da alface longitudinalmente, assim, possibilitando a exposição do caule, onde se efetuou a medição, com uso de uma régua.

As análises de regressão foram realizadas seguindo esquema sugerido por Pimentel Gomes (1990).

\section{RESULTADOS E DISCUSSÃO}

Todas as características avaliadas foram influenciadas pelas doses do composto orgânico utilizado. A massa fres- 
ca total evidenciou efeito quadrático, na qual a produtividade máxima de 914,2 g planta ${ }^{-1}$, foi obtida com a dose de 59,4 t ha $^{-1}$ do composto orgânico (Figura 1). Estes resultados são superiores aos obtidos por Fontanetti et al. (2002), que avaliaram a mesma cultivar, nas condições de Lavras e obtiveram a melhor resposta, em termos de rendimento, com a dose de 40,0 t ha-1. Já Santos et al. (1994), verificaram que a máxima produção de matéria fresca $(321,69 \mathrm{~g}$ plan$\mathrm{ta}^{-1}$ ) foi obtida com a dose de $65,69 \mathrm{tha}^{-1}$ de composto orgânico, com base na matéria seca, ocorrendo decréscimos com o incremento das doses.

Resultados similares foram observados para massa fresca comercial, sendo a máxima produtividade $(634,3 \mathrm{~g}$ plan$\mathrm{ta}^{-1}$ ), obtida com a dose de $56,1 \mathrm{tha}^{-1}$ do composto orgânico (Figura 1). Para a indústria, alface americana com elevados peso e tamanho de cabeça comercial são desejáveis, pois estão diretamente relacionadas ao rendimento no momento do processamento. O uso de $56,1 \mathrm{tha}^{-1}$ de composto orgânico, neste trabalho, permitiu incremento de $21 \%$ no rendimento comercial, quando comparado com a testemunha. Heredia et al. (1996), verificaram incrementos significativos no cultivo de alface $(54,61 \%)$ em relação à testemunha quando na incorporação de $14 \mathrm{t} \mathrm{ha}^{-1}$ de cama de galinha. Diversos autores relatam a aplicação de adubos orgânicos proporcionando aumentos significativos na produtividade da alface (Schneider,1983; Nicoulaud et al., 1990; Ricci et al., 1994; Vidigal et al., 1995; Trani et al., 2000).

Para a circunferência de cabeça comercial, a maior medida, $41,4 \mathrm{~cm}$, foi obtida com a dose de 53,7 tha-1 (Figura 2). Essa dose possibilitou incremento de $21 \%$ na circunferência da cabeça comercial em relação à testemunha. Efeitos positivos no incremento da circunferência da planta são também relatados por Vidigal et al. (1995).

O comprimento de caule é característica importante para a indústria, pois está diretamente relacionado ao rendimento da matéria prima. O caule é descartado no momento do processamento, sendo assim, caules muito compridos, acima de $7 \mathrm{~cm}$, representam perda de

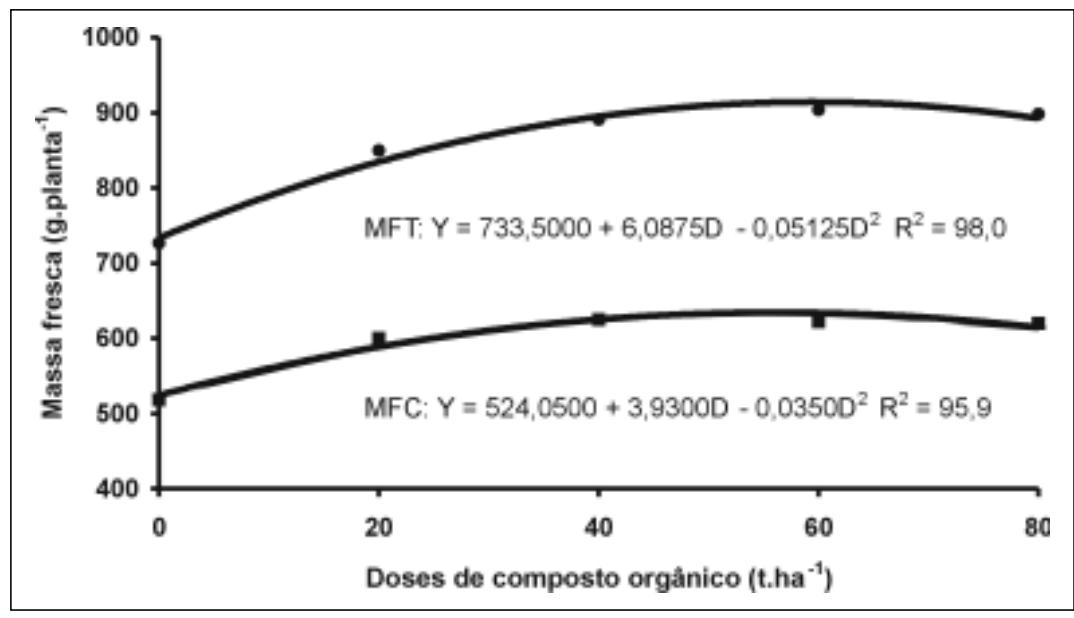

Figura 1. Massa fresca total (MFT) e comercial (MFC) de alface americana, cultivar Raider, em função de doses de composto orgânico. Santana da Vargem (MG), UFLA, 2002.

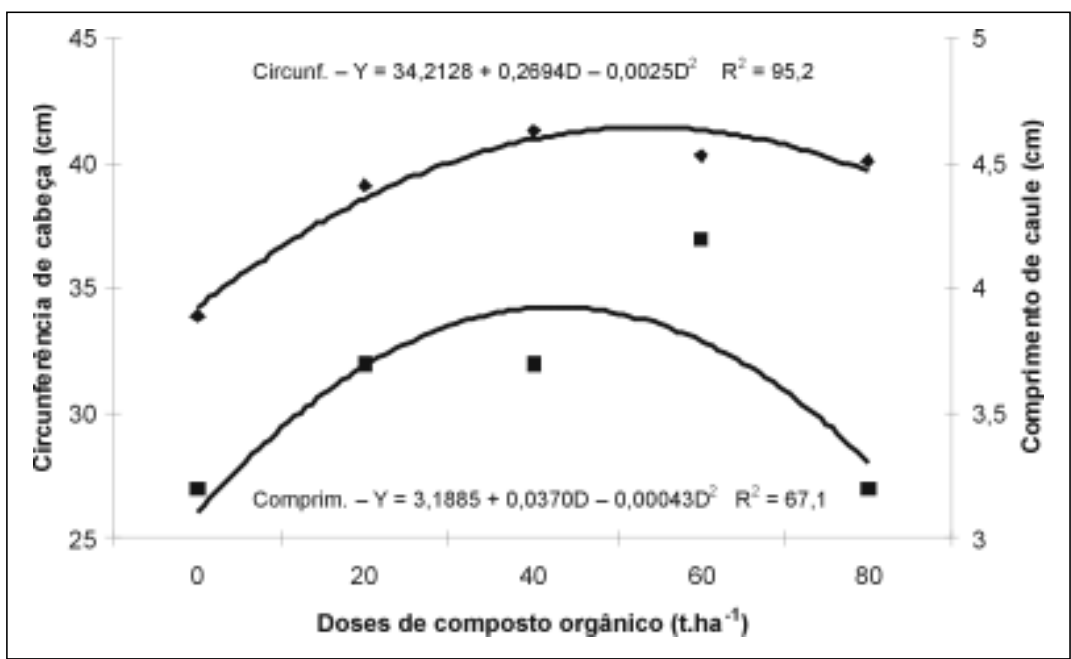

Figura 2. Circunferência de cabeça comercial e comprimento de caule de alface americana, cultivar Raider, em função de doses de composto orgânico. Santana da Vargem (MG), UFLA, 2002.

material e, conseqüentemente, diminuição no rendimento. Neste experimento, houve efeito significativo entre os tratamentos para o comprimento de caule. A dose de 42, $7 \mathrm{t} \mathrm{ha}^{-1}$ proporcionou comprimento máximo de $3,9 \mathrm{~cm}$ (Figura 2). Esta medida está dentro de valores aceitáveis pela indústria. Em termos de comprimento de caule, para a cultivar Raider, Yuri (2000), obteve valores de 3,6 e $4,5 \mathrm{~cm}$, nas condições de Santo Antônio do Amparo (MG) e, 2,7 e 3,2 $\mathrm{cm}$, em Boa Esperança, em função de épocas de plantio.

Nas condições em que foi realizado o experimento e para o tipo de composto orgânico utilizado, conclui-se que o uso de 56,0 t ha ${ }^{-1}$ aplicado em pré-plantio, proporciona melhor rendimento e qualidade comercial da alface americana.

\section{LITERATURA CITADA}

CASTRO, R.P.; FERRAZ JR, A.S.L. Teores de nitrato nas folhas e produção da alface cultivada com diferentes fontes de nitrogênio. Horticultura Brasileira, Brasília, v.16, n.1, p.65-68, 1998.

COSTA, C.A. Crescimento e teores de sódio e de metais pesados na alface e na cenoura adubadas com composto orgânico de lixo urbano. 1994. 89 p. (Tese mestrado), UFV, Viçosa.

DECOTEAU D.R.; RANWALA, D.; McMAHON M.J.; WILSON, S.B. The lettuce growing handbook: botany, field procedures, growing problems, and postharvest handling. Illinois: Oak Brook, 1995. 60 p. 
FONTANETTI, A.; ALMEIDA, K.; SOUZA, A.V.; CARVALHO, G.J. Adubação orgânica e química com e sem aplicação de resíduo siderúrgico, na produção de alface americana Horticultura Brasileira, Brasília, v.20, n.2, Suplemento 2, 2002. (CD-ROM).

HEREDIA Z., N.A.; VIEIRA, M.C.; CABEÇAS Jr., O. Influência de cama de aviário semi-decomposta em cobertura e incorporada sobre a produção de alface 'Grand Rapids' em Dourados-MS. Horticultura Brasileira, Brasília, v.14, n.1, p.89, 1996. (Resumo).

MALUF, W.R. Melhoramento genético de hortaliças. Lavras. UFLA, 2000. 183 p. Apostila.

MENDONÇA, E.S. Características e propriedades da matéria orgânica e a produção de composto convencional, vermicomposto e super magro. In: ENCONTRO MINEIRO SOBRE PRODUÇÃO ORGÂNICA DE HORTALIÇAS, 1, 1998 , Viçosa. Anais... Viçosa: UFV, 1998. p.56-77. MIYASAKA, S.; NAKAMURA, Y.; OKAMOTO, H. Agricultura natural. 2. ed. Cuiabá: SEBRAE/MT, 1997. 73 p. (Coleção agroindústria).
NICOULAUD, B.A.L.; MEURER, E.J.; ANGHINONI, I. Rendimento e absorção de nutrientes por alface em função de calagem e adubação mineral e orgânica em solo "areia quartzosa hidromorfica". Horticultura Brasileira, Brasília, v.8, n.2, p.6-9, 1990

PIMENTEL GOMES, F. Curso de estatística experimental. 13.ed. São Paulo: Nobel, 1990. 468 p. RIBEIRO, A.C.; GUIMARÃES, P.T.G.; ALVAREZ V.V.H. Recomendações para o uso de corretivos e fertilizantes em Minas Gerais. Viçosa: CFSEMG, 1999. 359 p. (5 aproximação).

RICCI., M.S.F. Produção de alface adubadas com composto orgânico. Horticultura Brasileira, Brasília, v.12, n.1, p.56-58, 1994.

SANTOS, R.H.S.; CASALI, V.W.D.; CONDÉ, A.R. ; MIRANDA, L.C.G. Qualidade de alface cultivada com composto orgânico. Horticultura Brasileira, Brasília, v.12, n.1, p.29-32, 1994.

SCHNEIDER, L. Rendimento e qualidade de alface em função da adubação nitrogenada, orgânica e mineral. 1983. 69 p. (Tese mestrado), UFRGS, Porto Alegre.
SILVA, L.H.; NEGREIROS, M.Z.; PEDROSA, J.F. Produção de alface adubada com composto orgânico na presença e ausência de adubo mineral. Horticultura Brasileira, Brasília, v.16, n.1, 1998. (Resumo 320).

TRANI, P.E.; TAMISO, L.G.; TESSARIOLI NETO, J.; HASS, F.J.; TAVARES, M.; BERTON,

R.S. Adubação orgânica da alface de verão sob cultivo protegido. In: CONGRESSO BRASILEIRO DE OLERICULTURA, 42, 2000, São Pedro. Anais... São Pedro: SOB/FCAV-UNESP, 2000. p.762-764.

VIDIGAL, M.V.; RIBEIRO, A.C.; CASALI, V.W.D.; FONTES, L.E.F. Resposta da alface (Lactuca sativa L.) ao efeito residual da adubação orgânica. I. Ensaio de campo. Revista Ceres, Viçosa, v.42, n.239, p.80-88, 1995.

YURI J.E.; MOTA, J.H.; SOUZA, R.J.; RESENDE, G.M.; FREITAS, S.A.C.; RODRIGUES JUNIOR, J.C. Alface americana: cultivo comercial. Lavras: UFLA, 2002. 51 p. (Texto acadêmico)

YURI, J.E. Avaliação de cultivares de alface americana em duas épocas de plantio e dois locais do sul de Minas Gerais. Lavras. 2000. 51 p. (Tese mestrado), UFLA. 